\section{P2.39 COMPLETE REVERSAL OF AN ABERRANT TUMOUR BY KAPOSI'S SARCOMA IN A PATIENT WITH HIV USING HAART PLUS LIPOSOMAL DOXORUBICIN}

SR Pimentel, S Tenore, I Giarolla, CM Gamba. Centro de Referência e Treinamento em DSTI AIDS, Brazil

\subsection{6/sextrans-2017-053264.215}

Introduction Kaposi's Sarcoma (KS) is the most common HIV related neoplasm since the outburst of the HIV epidemic in early 1980s. After the widespread use of highly active antiretroviral therapy (HAART) its incidence has declined drastically, but even today patients find themselves infected with HIV after developing KS.

Methods Case Report.

Results We report the case of a 36 years old, African-american, bisexual man who had his HIV diagnosis on october 2014 after the onset of violaceous, nodular skin lesions all over his body six months earlier. At first visit to our service he has presented with 70 skin lesions, 69 of them were violaceous and nodular, one oral mucous lesion and typical biopsyproven gastric and sigmoid lesions. His CD4 count was 99 cels/mm3 and HIV viral load was 3412 copies/mm3 (log 3.533). His KS was classified as T1S1. The most disturbing finding, though, was an aberrant presentation of KS on his $2^{\text {nd }}$ left pododactyl, affecting and disturbing the entire normal architecture of this toe, making it three times bigger than usual, displacing the fingernail, along with other nodular lesions on the dorsal face of the left feet.This lesion was very secretive, with a clear and foetid fluid. Patient had already started TDF/3TC/EFZ plus sulfametoxazol-trimetoprim 1 week earlier and we prescribed liposomal doxorubicin, $20 \mathrm{mg} / \mathrm{m}^{2}$ each 21 days, alongside with special dressings on this tumoral lesion thrice a week. He achieved undetectable viral load and CD4 cell count of 117 cells $/ \mathrm{mm}^{3}$ four months later. Patient received 26 chemotherapy sessions from December 2014 to April 2016, with a total dosage of $852 \mathrm{mg}$ of liposomal doxorubicin and achieved a complete response, with healing of all skin, mucous and visceral lesions, including a full recovery of the $2^{\text {nd }}$ pododactyl.

Conclusion A combination of HAART plus extensive chemotherapy and proper dressings was successful to completely heal an unusual aberrant tumour in a patient with disseminated KS.

\section{P2.40 ANOGENITAL WART WITH ATYPICAL MORPHOLOGICAL FEATURES IS NOT ALWAYS AN ALARMING SIGNAL FOR THE TREATING PHYSICIAN}

${ }^{1}$ Somesh Gupta, ${ }^{1}$ Pankaj Kumar, ${ }^{1}$ Neetu Bhari, ${ }^{1}$ Vishal Gupta, ${ }^{2}$ Vg Ramachandran, ${ }^{1}$ Sudheer Arava, ${ }^{1}$ Lalit Dar, ${ }^{1}$ Vinod K Sharma, ${ }^{1}$ Kaushal K Verma, ${ }^{1}$ Sada Nanad Dwivedi. 1. All India Institute of Medical Sciences, New Delhi, India; ${ }^{2}$ University College of Medical Sciences, New Delhi, India

\subsection{6/sextrans-2017-053264.216}

Introduction The clinical morphology of anogenital warts may vary from flat, filiform, popular or verrucous to giant condyloma acuminata, and Buschke-Löwenstein tumour. Clinically atypical-looking genital warts may alarm the clinician because of their suspected malignant potential, which may cause anxiety, often leading to aggressive interventions. We conducted this study to find out whether clinically atypical-looking anogenital warts are more likely to be premalignant or malignant as compared to typical warts.

Methods Data of forty-one (37 males, 4 females) patients with anogenital warts was retrospectively analysed. After a detailed literature review and in-house discussions, criteria for anogenital warts with typical and atypical clinical morphology were defined. Clinical photographs of the anogenital warts were independently reviewed by three dermatologists, and HPV genotyping results, histological evaluation, and immunohistochemical analysis for p53 expression were evaluated.

Results Fifteen (36.6\%) anogenital warts were classified as atypical by at least two out of three blinded dermatologists. The histological examination showed mitotic figures in $29 / 41$ (70.8\%), dysplasia in 14/41 (44.1\%) specimens and p53 positivity in $34 / 41(82.9 \%)$ of specimens. There was no significant difference in the high-risk HPV genotyping $(p=0.6)$, frequency of dysplastic changes on histology $(\mathrm{p}=0.3)$ and immunohistochemistry with $\mathrm{p} 53(\mathrm{p}=0.07)$ between clinically typical and atypical-appearing anogenital warts. Similarly, no significant difference was found in the frequency of dysplastic changes $(p=0.3)$ or $p 53$ expressions $(p=0.5)$ based on the HPV genotypes.

Conclusion The atypical clinical morphology of anogenital warts may not be a marker of increased malignant potential. High-risk HPV genotypes do not have a statistically significant association with dysplasia or positive immunohistochemistry with p53.

Support: The part of the study was done with financial support from Department of Biotechnology, Government of India

\section{P2.41 PHARMACEUTICAL ASSISTANCE IN SYPHILIS PATIENT CARE - FROM PREVENTION TO SUCCESSFUL TREATMENT}

'Stephanie Berzin Grapiglia, ${ }^{2}$ Bruna Portela de Lima. 1. Coordenadoria da Área Programática 3.2 - Prefeitura Municipal do Rio de Janeiro, Rio de Janeiro - RJ, Brazil; ${ }^{2}$ Organização Social Sociedade Paulista pelo Desenvolvimento da Medicina/SPDM, Rio de Janeiro - RJ, Brazil

\subsection{6/sextrans-2017-053264.217}

Introduction The expansion of Family Health in the City of Rio de Janeiro, as well as the structure that minimally requires one pharmacist per unit of Family Health Clinic, this professional has been often acting as protagonists in the success of the Treatment and follow-up. In this context, the pharmacist performance in all stages of syphilis care has become paramount for the success of the treatment, acting in all care stages.

Methods Prevention - opportunize the patient's visit to the pharmacy to identify individuals risk and eligible for actions as pharmaceutical consultation or a educational group, as responsible for the custody and control of the syphilis Rapid test allows the knowledge of the cases even before the dispensation. Surveillance and notification of public health problems - as soon as the knowledge of the diagnosis, by rapid test result or the demand for the dispensing of the medicine, is also responsible for that notification, and it is up to him to make that request to the professional who made the diagnosis 